\title{
NEIBA
}

\section{Da Guerra às Drogas ao Plano Colômbia: uma agenda securitária dos Estados Unidos para a América do Sul}

\author{
Maria Aparecida Felix Mercadante
}

Vínculo Institucional: Estudante da Especialização em Relações Internacionais Contemporâneas da Universidade Federal da Integração Latino-Americana (UNILA). Email: mariaamercadante@hotmail.com.

\section{Resumo:}

Em 1971, o presidente norte-americano Richard Nixon declarou o abuso de drogas como sendo o inimigo público número um dos Estados Unidos. A partir disso, o discurso e o direcionamento das políticas norte-americanas contra as drogas basearam-se na divisão do mundo entre dois grupos: os países produtores de ilícitos e os países consumidores. Os Estados Unidos, como pertencentes do grupo de países consumidores, se posicionam como "vítimas", gerando uma retórica de segurança nacional. O objetivo do presente trabalho é analisar a securitização do narcotráfico pelos Estados Unidos e o desenvolvimento do Plano Colômbia como um caso de overlay dos interesses norte-americanos. O alinhamento do aparato discursivo entre os dois países moldou uma estratégia repressiva que garantiu uma política cujo eixo central era o caráter bélico, principalmente após 0 11/9, com a campanha militar conhecida como Plano Patriota e a incorporação da guerra às drogas pela guerra ao terror.

Palavras-chaves:

Colômbia; narcotráfico; Plano Colômbia; securitização; Estados Unidos.

\begin{abstract}
:
In 1971, the North American President Richard Nixon declared drug abuse as being United States number one public enemy. Since then, the discourse and the targeting of North American policies against drugs were based on the world being divided into two groups: countries producers of illicit and consumer countries. The United States, belonging to the consumer countries group, portrait themselves as "victims", creating a national security rhetoric. The objective of the present essay is to analyze drug trafficking securitization by the United States and Plan's Colombia development as an overlay case of North American interests. The
\end{abstract}




\section{NEIBA}

\section{VOLUME VII}

Dossiê: SimpoRI 2018

\section{8}

alignment of the discursive apparatus between the two countries molded a repressive strategy that ensured policies which their main axis was the military character, mainly after 9/11, with the military campaign known as Patriotic Plan and the incorporation of the war against drugs by the war against terror.

\section{Keywords:}

Colombia; drug trafficking; Plan Colombia; securitization; United States. 


\section{NEİBA}

\section{Introdução}

A Escola de Copenhague nasce no seio das abordagens definidas como "amplificadoras" e "aprofundadoras" ${ }^{1}$ dos Estudos de Segurança Internacional que emergiram com maior força após a Guerra Fria. A partir das contribuições de Barry Buzan e Ole Waever, a Escola se coloca de forma intermediária dentro do debate existente entre a "segurança individual" ou "global", dos Estudos Críticos de Segurança e Pesquisa da Paz, e o estadocentrismo tradicional presente nos Estudos Estratégicos. Relacionando a prática discursiva e as questões de segurança, os autores desenvolveram o conceito de "securitização", baseando-se na ideia de que a definição de segurança depende de uma construção bem-sucedida no discurso.

Questões de segurança são construídas pelas práticas sociais e o processo de construção dessas questões é realizado por meio de discursos proferidos pelos atores mais interessados em estabelecer as agendas de segurança (TANNO, 2003). A securitização seria uma força discursiva capaz de mobilizar determinadas questões que anteriormente não seriam tratadas na forma de ameaças à segurança, mas que após o processo de securitização legitimam medidas extraordinárias de ação. De acordo com Buzan, Waever e Wilde (1998) segurança é, portanto, uma prática autorreferida uma vez que é em determinado contexto em que esta se torna uma questão de segurança não necessariamente porque haja uma ameaça existencial real, mas porque é apresentada como ameaça. É o meio pelo qual um agente securitizador busca estabelecer a existência de uma ameaça à sobrevivência de uma determinada unidade. Emprega-se o conceito de "ato de fala" (speech-act) para analisar o processo comunicativo por meio do qual um agente aplica um caráter de emergência a uma questão

${ }^{1}$ Construtivismo, que se divide em convencional e crítico; Segurança Humana; Pós-colonialismo; Estudos Críticos de Segurança; Pósestruturalismo; e, Feminismo são exemplos de outras abordagens (BUZAN, HANSEN, 2012). política. Ao mobilizá-la para o campo da segurança, o objetivo é proteger o objeto referente (a unidade) e legitimar o uso de medidas extraordinárias de exceção a fim de conter a potencial ameaça. A dessecuritização constitui-se no caminho inverso, pelo qual um objeto perde o status de ameaça, transferindo-se assim da esfera de segurança para a esfera política. (BUZAN, WAEVER, WILDE, 1998; DUQUE, 2009).

Questões políticas podem, portanto, sofrer processos de securitização ou dessecuritização, podendo assim explicar por que temas são transportados da esfera política para a esfera de segurança em determinados contextos históricos e políticos. Cabe apontar que o processo de securitização depende da aceitação do público; o ator securitizador, por meio do ato discursivo, deve ser capaz de persuadir o público a visualizar a questão como uma ameaça à segurança, colocando-a acima de outras questões de segurança, "If by means of na argument about the priority and urgency of an existential threat the securitizing actor has managed to break free of procedures or rules he or she would otherwise be bound by, we are witnessing a case of securitization" (BUZAN, WAEVER, WILDE, 1998 p. 25).

Além do conceito de securitização, no tocante a proposta do presente trabalho, cabe ainda tratar do conceito de overlay cunhado pela Teoria dos Complexos de Segurança Regionais desenvolvido por Buzan e Waever, quando "direct presence of outside powers in a region is strong enough to suppress the normal operation of security dynamics among the local states" (BUZAN, 1991 p.198). Têm-se como consequência a sobreposição de interesses e estratégias externas na segurança de determinado Estado ou região, influenciando, nesse sentido, a securitização de determinados objetos de referência.

O objetivo do presente trabalho, portanto, é analisar a securitização do narcotráfico pelos Estados Unidos e o desenvolvimento do Plano Colômbia, em 2000,como um caso de overlay dos interesses norte-americanos. $O$ estudo 


\section{NEIBA}

está estruturado em três seções. Na primeira, será abordada a evolução da questão das drogas em território norteamericano, abordando a criação da campanha "guerra às drogas" e a utilização de uma retórica de segurança nacional e regional, com a vinculação dos grupos insurgentes com a economia da droga - "narcoguerrilhas" -, que legitima políticas intervencionistas norte-americanas na América Latina. O foco da segunda seção será o campo discursivo utilizado para a apresentação da Colômbia como um país "problema", um exemplo de "narcodemocracia", e a internacionalização do conflito colombiano a partir da criação do Plano Colômbia. Por sua vez, a terceira seção analisará a incorporação da "guerra às drogas" pela "guerra ao terror" após o 11/09 e a transformação do caso colombiano em "narcoterrorismo".

\section{As drogas em território norte-americano: Nixon,}

\section{Reagan, Bush e Clinton}

A política conhecida como "guerra às drogas", no original "war on drugs", foi concebida a partir do discurso do presidente norte-americano Richard Nixon (1969-1974), em 1971, em que este anunciou "America's public enemy number one in the United States is drug abuse" (Discurso de Richard Nixon. Estados Unidos, 1971). A partir disso, o discurso e a articulação das políticas contra as drogas basearam-se na divisão do mundo entre os países produtores de ilícitos e os países consumidores; os Estados Unidos como pertencentes do grupo de países consumidores, se posicionaram como "vítimas" de grupos ilegais. Nixon promove o primeiro movimento na securitização do narcotráfico, mobilizando-o de uma questão de política normal para o campo da segurança, qualificando-o como uma ameaça à segurança nacional norte-americana. A construção da ideia de que as drogas são o inimigo número um do Estado norte-americano legitima o uso de medidas excepcionais em nome da defesa do Estado e da sociedade,de modo que a aplicação dessas medidas será feita tanto em âmbito interno quanto externo.
Assim, em 1973, os EUA criam a Drug Enforcement Administration (DEA), agência que centraliza o planejamento das ações antidrogas, responsável pela reformulação do aparato repressivo norte-americano e pelas primeiras operações contra o narcotráfico no Caribe e no México. A retórica antidrogas, empregada por Nixon, unia o crime com o consumo de drogas como parte de um programa de ordem pública e defendia o tratamento com políticas anticrime. Esse tipo de discurso, como consequência, exacerbava os medos da população em relação aos usuários de drogas (RODRIGUES, 2012; TATE, 2015). Assim, a política de combate às drogas ganhava cada vez mais espaço na agenda norte-americana e, sobretudo, nas relações entre os Estados Unidos e os países da América Latina.

A militarização no combate às drogas foi reforçada no governo de Ronald Reagan (1981-1989), que de acordo com Santos (2007, p.171) "retomou os valores do moralismo puritano e da ética protestante do trabalho para lançar uma grande cruzada contra as drogas". Essa política era subordinada às diretrizes de política-externa norteamericana, portanto, o problema da proliferação do uso das drogas não era diagnosticado como questão de saúde pública interna, de desajuste social ou da própria política proibitiva interna que vingava desde os anos 6o, mas como uma questão de segurança nacional imposta pelo governo norte-americano. A colocação dos grupos insurgentes como responsáveis pela proliferação do tráfico de cocaína veio em 1986, quando Reagan incorpora a Doutrina de Segurança Nacional em uma "National Security Decision Directive 221" (NSDD-221), intitulada "Narcotics and National Security", e afirma que "some insurgent groups finance their activities through taxing drug activities, providing protection to local criminal traffickers, or growing their own drug crops. Access to money available from narcotics can have a major impact on the capability of the insurgent forces." (UNITED STATES, 1986, p. 2).

Desse modo, ainda que não constassem nominalmente quais eram os grupos insurgentes, a 


\section{NEIBA}

administração Reagan foi responsável pela primeira associação entre as guerrilhas latino-americanas e o tráfico de cocaína. Essa associação levou à criação de uma nova ameaça - dessa vezà segurança continental - que ganharia a denominação de "narcoguerrilha". O trabalho institucional e ideológico que permitiu a criação da ameaça advinda desses novos inimigos foi baseado na lógica da política pública estadunidense do período da Guerra Fria, ou seja, as guerrilhas, além de serem discursivamente aproximadas do narcotráfico, eram acusadas de propagarem o comunismo. A necessidade de conter o comunismo tornou possível a personificação desses inimigos seguindo os interesses nacionais norte-americanos (TATE, 2015). O caráter continental da ameaça é evidenciado no mesmo documento,

the national security threat posed by the drug trade is particularly serious outside U.S. borders. of primary concern are those nations with a flourishing narcotics industry, where a combination of international criminal trafficking organizations, rural insurgents, and urban terrorists can undermine the stability of the local government [...] While these problems are endemic to most nations plagued by narcotics, their effects are particularly insidious for the democratic states of the Western Hemisphere. Moreover, the expansion of narcotics activity creates a regional problem (UNITED STATES, 1986, p. 1).

Essa ameaça foi amplamente utilizada na forma propagandista, para que se criasse na população um clima de apoio a um envolvimento mais efetivo e mais direto por parte do governo norte-americano no combate ao narcotráfico, inclusive no âmbito militar (RODRIGUES, 2012; SANTOS, 2007). Reagan aprofundou o processo de securitização do narcotráfico anunciada pelo governo Nixon:de uma ameaça à segurança nacional estadunidense, o narcotráfico passa a ser tratado como uma ameaça à segurança regional e as medidas extraordinárias de ação passam a pautar os documentos oficiais. Na NSDD-221, para conter essa "ameaça", estava previsto o desenvolvimento e a implementação, a partir de um trabalho conjunto do secretário da Defesa, do procurador-geral e do secretário de Estado, de qualquer modificação necessária aos estatutos e regulamentos para que as Forças Armadas dos EUA pudessem dar um suporte mais ativo no combate ao narcotráfico (UNITED STATES, 1986). Com isso, as Forças Armadas norte-americanas estavam autorizadas a trabalhar diretamente em operações antinarcóticos no exterior.

A adesão dos países latino-americanos na "guerra contra as drogas" se deu a partir de pressões diplomáticomilitares dos EUA sobre os mesmos, como demonstrado por Serrano e Toro "a política antidrogas dos Estados Unidos incluía a colaboração de muitos governos latino-americanos, que receberam cada vez mais ajuda econômica e técnica, adotaram programas de capacitação da polícia dos EUA e se converteram em anfitriões de numerosos agentes da DEA" (2005, p. 242-243 apud RODRIGUES, 2012). Exemplo dessa dinâmica, a Operação Blast Furnance, de 1986, desembarcou forças militares norte-americanas na Bolívia com objetivo de reduzir o preço de mercado da folha de coca a partir da destruição de laboratórios e centros de produção de cocaína (MALAMUD-GOTI, 1990).

A partir da criação da Anti-Drug Abuse Act, em 1986 e, em 1988, de uma emenda ao The Foreign Assistance Act of 1961, o governo norte-americano inicia um processo de "certificação"2 pelo qual, anualmente, o seu presidente passaria a publicar a lista dos países que, de acordo com o julgamento dos EUA, tinham colaborado ou não com a política de "guerra às drogas". Para os países que fossem consideração como "não cooperativos" havia a previsão de sanções, como a suspensão de ajuda norte-americana ou a oposição dos EUA à empréstimos de bancos de desenvolvimento regionais e multilaterais (ROGRIGUES, 2012; GDPO, 2016).

\footnotetext{
2 The Narcotics Certification Process foi encerrado pela Foreign Relations Authorization Act, 2002-2003.Dados disponíveis emhttp://www.state.gov/j/inl/rls/rpt/c11766.htm
} 


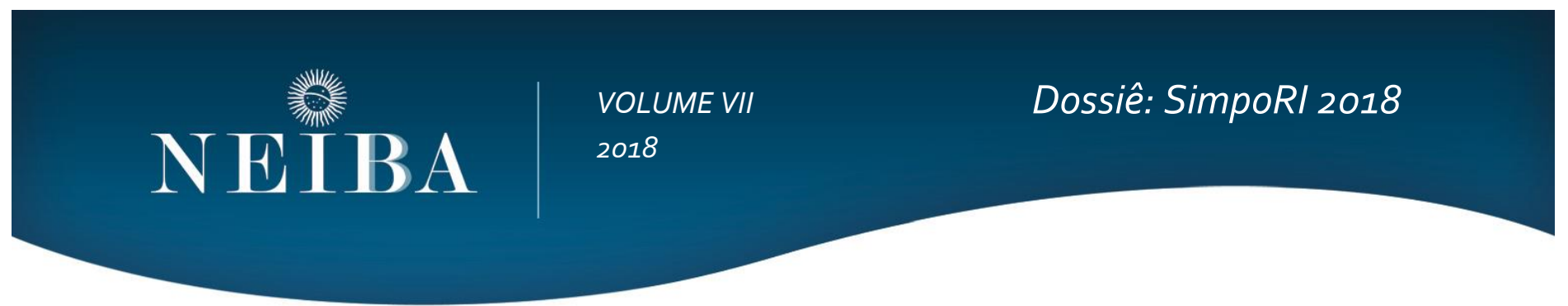

O aprofundamento damilitarização da luta contra o narcotráfico ocorre durante o governo de George H. W. Bush (1989-1993) com a edição, em 1989, de outra diretiva, a National Security Directive 18. Esta reforça o narcotráfico como uma ameaça regional e apresenta a estratégia norteamericana de política antinarcóticos para a Região Andina, intitulada de International Counter narcotics Strategy. Conforme o texto original,

the impact of illegal narcotics use on our society has been and continues to be devastating. Moreover, the violence and corruption of the drug traffickers and their alliance with insurgent groups has had a destabilizing effect on friendly governments. It is thus imperative for our own well-being and the development of democratic and economically stable governments around the world that this problem be dealt with aggressively (UNITED STATES, 1989 p.1).

A Colômbia é descrita "as the horne of the major trafficking organizations and the principal production facilities for U.S. destined" (UNITED STATES, 1989 p. 1-2), sendo, portanto, a justificativa para priorizar a região. A política,que também abarcaria Peru e Bolívia, éconhecida como Iniciativa Andina e tinha como objetivo promover assistência militar, treinamento e apoio logístico a esses países. Visando a efetiva redução da oferta da droga, o governo Bush considerava a militarização a única saída para resolver a situação da segurança ${ }^{3}$. Segundo dados do US Goverment Accountability Office (GAO), presentes no trabalho de Buono (2001 p.214), entre 1989 e 1994 foram gastos 2.147 milhões de dólares na Região Andina, sendo a metade destinada à

3 Esforços multilaterais em matéria de combate ao narcotráfico foram pauta da Cúpula de Cartagena, em 1990, e da Cúpula de Santo Antônio em 1992. Entretanto, a desconfiança a respeito das medidas repressivas, bem como das condicionantes econômicas de ajuda financeira, adotadas pela política externa norte-americana, levaram os países a negar a proposta do governo norte-americano para criação de um grupo de ação regional, uma força militar multilateral de combate ao narcotráfico, entendendo que esta poderia permitir ações intervencionistas - como aconteceu no Panamá desrespeitando a soberania dos países envolvidos (SANTOS, 2007); PROCÓPIO FILHO; VAZ, 1997). assistência militar e a DEA e a outra metade a diferentes formas de assistência econômica.

Com a Operação BlastFurnace, o processo de Certificação e a Iniciativa Andina, fica cada vez mais evidente a ingerência norte-americana na região. As estratégicas de combate ao narcotráfico eram formuladas e executadas de acordo com os interesses estadunidenses, dado os recursos financeiros investidos por estes, o apoio operacional e tecnológico e pela pressão exercida sobre os países latinoamericanos de serem considerado "não-cooperativos" na "guerra às drogas". Cabe recordar dois exercícios militares do governo Bush quedemonstraram a força, o interesse e a unilateralidade norte-americana no continente: o primeiro, em 1989, é conhecido Operação Causa Justa, no qual o exército norte-americano invade o Panamá para prender o então presidente Manuel Noriega - ex-aliado do governosob acusação de narcotráfico; o segundo, em 1990, o DEA prende em território mexicano - e sem a consulta do governo local - o médico Humberto Alvarez Machaín sob a acusação de participar do assassinato de um agente da DEA México (SANTOS, 2007).

O governo de Bill Clinton (1993-2001) promove uma nova política antinarcóticos. A National Drug Control Strategy, de 1994, apresenta como pontos focaisdessa nova política quatro estratégias: três são de ação no plano doméstico e uma no plano internacional "iv) Changes in how the United States carries out international drug control policy to refocus interdiction's emphasis from the transit zones to the source countries" (UNITED STATES, 1994 p.1). O governo norte-americano reconhece a necessidade de mudar o modo como a política antinarcóticos era executada até então, voltando sua atenção do combate à oferta para o combate à demanda. No que diz respeito ao plano internacional, mantêm-se as bases de cooperação internacional e afirma o recrudescimento da posição norte-americana para os países que não se mostrarem cooperativos. 


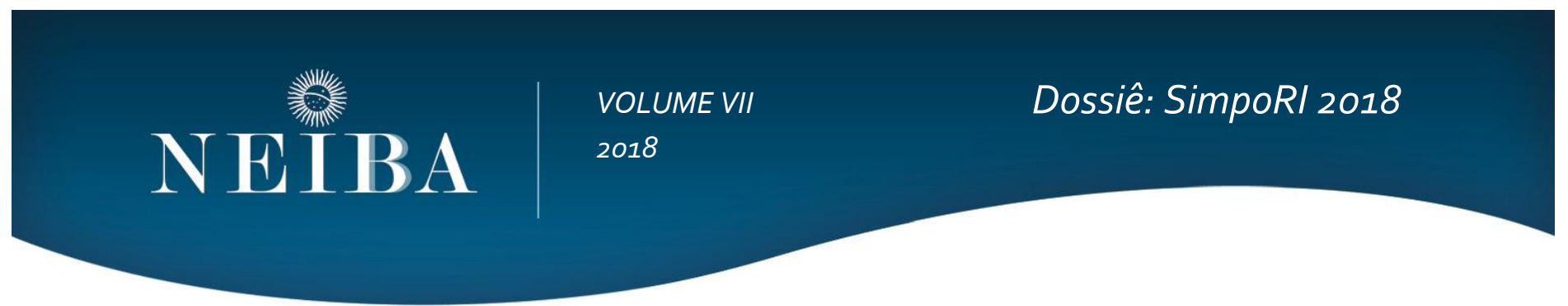

[...] It is in the national interest to maintain this role [continue to lead the international antidrug effort], but the assistance offered to other countries will no longer be unconditional. The United States will work closely with those countries that demonstrate the political will and commitment to undertake serious counternarcotics programs. However, those drug producing and trafficking countries that do not make an effort will face increasingly serious economic and other sanctions, including more aggressive use of the congressionally mandated certification process that conditions economic and military assistance on counternarcotics performance.(UNITED STATAES, 1994 p.51)

Entre 1987 e 2001, a Colômbia foi o único país da região andina que foi descertificado pelo governo norteamericano, e por dois anos consecutivos: 1996 e 1997. A descertificação foi resultado do escândalo envolvendo o financiamento, pelo Cartel de Cali, da campanha do então presidente Ernesto Samper ${ }^{4} \quad(1994-1998)$ (US CONGRESSIONAL RESEARCH SERVICE - (RS, 2003).O governo norte-americano, manifestando a insatisfação com o governo colombiano no combate ao narcotráfico e à expansão dos cultivos ilícitos, cancelou a visita ao presidente Samper em 1996. As pressões externas desembocaram no início da fumigação aérea com glifosato $(\mathrm{GMH}, 2013)$.

\section{Do discurso à prática: Plano Colômbia}

Conforme apresentado na introdução, uma das bases para o sucesso do processo de securitização é o convencimento do público de que medidas extraordinárias precisam ser aplicadas para conter a ameaça à unidade nacional. Nesse sentido, a política externa norte-americana empregada para o combate às drogas era legitimada pela

4 O escândalo é conhecido como "El Proceso 8.000", Samper foi inocentado pelo Congresso e se manteve na presidência até o fim de seu mandato. própria população: uma pesquisa publicada pela CBS News/NewYork Times, em 1988, mostrou que $48 \%$ dos norte-americanos consideravam as drogas o principal desafio da política externa dos EUA, e $63 \%$ acreditavam que as luta contra as drogas deveria ter precedência sobre a luta anticomunista (CRANDALL, 2002 p.32).

A permanência na "guerra às drogas" envolveainda além dos interesses ligados aos grupos militares, pressões de thinktanks norte-americanos ao governo central. Em 1994, o centro de pensamento conservador, Heritage Foundation, publicou o texto "How the Clinton Administration is Abandoning the War Against Drugs" em que acusa o governo Clinton de abandonar a liderança dos EUA no combate ao narcotráfico e dar uma nova direção para a "guerra às drogas" "[...] that new direction will allow more cocaine, heroin, and marijuana to reach American streets, and it will cut federal enforcement personnel."(HERITAGE FOUNDATION, 1994). No ano seguinte, em "Colombia's Narco-Democracy Threatens Hemispheric Security", Heritage Foundation volta a criticar a administração Clinton e sua aliança com a Colômbia na luta antinarcóticos, denunciando o país andino como uma narcodemocracia ${ }^{5}$ e cobrando uma posição mais assertiva do governo norte americano "the time has come to begin treating the Colombian government as part of the American drug problem rather than part of the solution [...] the U.S. should take the lead in isolating Colombia internationally" (HERITAGE FOUNDATION, 1995).

Na medida em que os funcionários do governo, os thinktanks e os militares advogavam por uma postura mais rígida e pela necessidade de incrementar a ajuda militar, o argumento de que não havia distinção entre a guerrilha e o narcotráfico ganhava mais destaque. A origem do termo "narcoguerrilha" é atribuída a Lewis Tambs, embaixador dos EUA na Colômbia, em meados dos anos 80, quando funcionários do governo passaram a advertir que os grupos

5 A Colômbia já tinha sido qualificada como uma narcodemocracia por Joe Toft, alto funcionário da (DEA), no ano anterior (GUTKIN, 1994). 


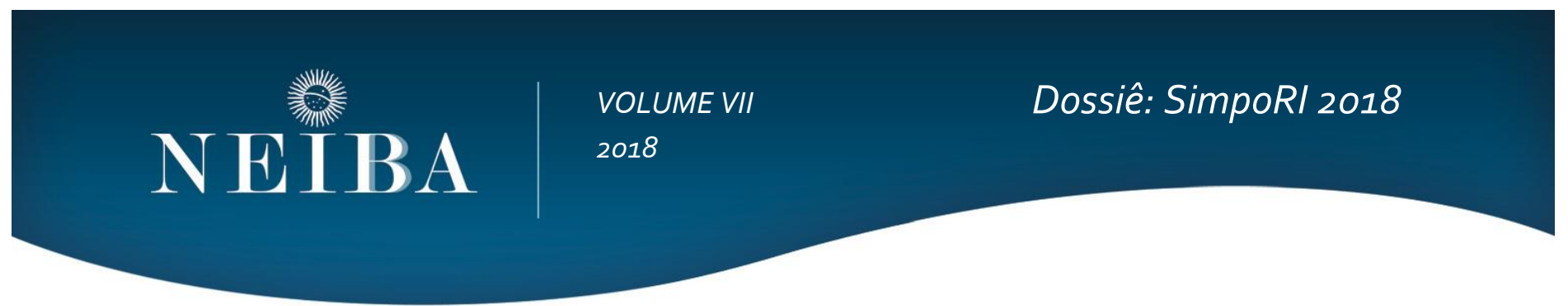

insurgentes da região se financiavam por meio da economia da droga. (TATE, 2015). A utilização desse conceito deslegitimava o caráter político dos movimentos de esquerda e justificava o incremento da ajuda militar norteamericana, já que uma vez categorizadas como organizações criminosas, as guerrilhas teriam acesso ilimitado a recursos do narcotráfico, representando uma ameaça real e permanente à região. A produção de inimigos por parte de agentes estatais com a finalidade de legitimar intervenções repressivas em determinadas comunidades é uma prática fundamental da militarização. Esse argumento era reforçado pelo maior envolvimento das Fuerzas Armadas Revolucionarias de Colombia (FARC) na economia da droga após a desmobilização dos grandes cartéis e pelas decisões estratégicas que impulsionaram sua expansão militar e territorial no fim dos anos $90^{6}$. O aumento brutal dos recursos financeiros da organização, oriundos de uma participação mais direta na economia da droga, propiciou a mudança do perfil de autodefensas que as FARC possuíam até os anos 80. A acumulação de recursos financeiros foi a garantia da autonomia da guerrilha como uma organização militar (PECÁULT, 2008; TICKNER, GARCÍA e ARREZA, 2011).

\footnotetext{
${ }^{6}$ No início do processo de estabelecimento da economia da droga em território colombiano, algumas culturas, laboratórios e rotas de exportação de cocaína foram instalados em áreas controladas pelas FARC, embora nem sempre fossem os iniciadores. De qualquer modo, em um primeiro momento, a guerrilha oferecia proteção aos colonos contra traficantes e contra as incursões realizadas pelas forças armadas, o financiamento de grande parte de suas operações advinha da cobrança de impostos. Mais tarde, em 1982, com a VII Conferência das FARC, a guerrilha decidiu estrategicamente utilizar o comércio das drogas para financiar a luta armada, e assim criou seus próprios laboratórios, estabelecendo relações comerciais com os narcotraficantes. Essa decisão é considerada um ponto de ruptura na história das FARC, dada a consequente expansão territorial e militar. Progressivamente, a guerrilha aumentou as taxas aos cultivadores e ampliou a proteção aos produtores intermediários, estabelecendo medidas de regularização, como a fixação de um preço único para a venda da pastabase e o cultivo paralelo de produtos agrícolas lícitos. Investimentos de infraestrutura também foram feitos, como a construção e manutenção de laboratórios, a proteção das rotas de tráfico e a introdução de insumos agrotóxicos (PECÁULT, 2008; TICKNER, GARCÍA e ARREZA, 2011).
}

É importante pontuar que o rótulo de "narcoguerrilha" negava a lógica política das FARC quanto a sua condição de guerrilha insurgente; distorcia a estrutura existente do narcotráfico naquele momento; ocultava os atores que estavam participando de forma mais direta e profunda do processo, como identifica Tate, "tildar a la organización guerrillera de narcoguerrilla implicaba colocar los falsamente en el centro del tráfico de drogas haciendo asi invisible la mayor presencia de los traficantes paramilitares aliados com las fuerzas militares colombianas" (2015 p. 38). Apesar de o discurso público ser dominado pela afirmação de que as FARC seriam o ator central do narcotráfico, declarações internas reportavam contradições existentes; em 1997, o embaixador estadunidense Myles Frechette ${ }^{7}$ confessou que "no todos los frentes [guerrilleros] se encuentran involucrados conel narcotráfico $y$, de aquellos que sí lo están, no puede decirse que constituyen un cartel" (TATE, 2015 p. 62). Assim, enquanto se ocultava estrategicamente o papel dos grupos paramilitares no tráfico de drogas - aliados das forças militares e institucionalmente legitimado pelo Decreto 356 de 1994 (COLOMBIA, 1994) ${ }^{8}$-, a campanha contrainsurgente e antinarcótico se transformava em uma só.

Para os formuladores de política pública dos EUA, as FARC como "narcoguerrilha" constituíram uma ameaça existencial antes de constituir uma ameaça fisicamente presente, isto por sua oposição multidimensional a um amorfo sistema de valores norte-americanos (TATE, 2015). Em 1998, o presidente do House International Relations

\footnotetext{
7 Frechette, embaixador entre 1994 e 1997, foi um dos embaixadores mais polémicos da história das relações diplomáticas entre EUA e Colômbia criticava abertamente os vínculos da campanha presidencial de Samper (1994-1998) e em 2007 afirmou em entrevista a rádio colombiana Caracol que advertiu o governo de Samper que as Convivir estavam se transformando em grupos paramilitares. A reportagem completa por ser vista em:

http://caracol.com.co/radio/2007/03/31/nacional/117532956o_409197.html 8 O Decreto 356 de 1994 regulava as Cooperativas de Vigilancia y Seguridad Privada "Convivir", tornando as autodefensas um esquema legal, autorizando a operação de grupos armados com vistas à "segurança individual".
} 


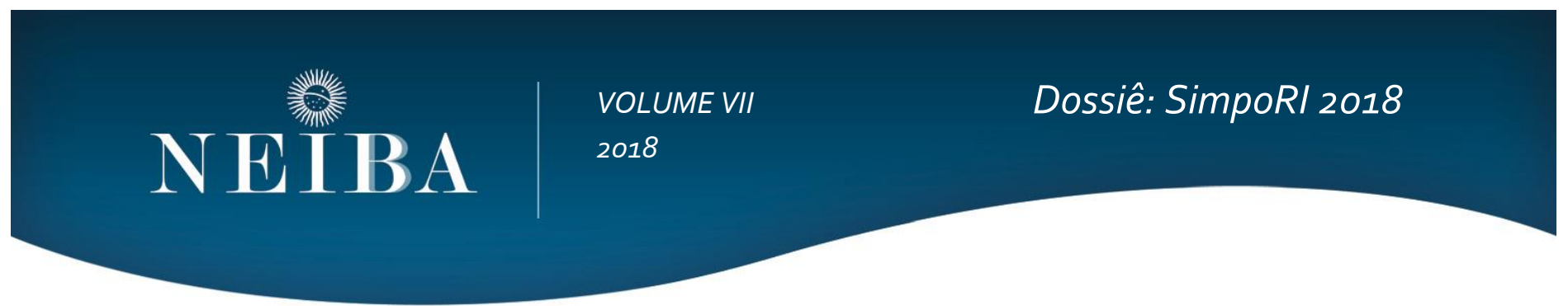

Comittee, o norte-americano Benjamin Gilman, afirmouque "the frightening possibilities of a narco-state just three hours by plane from Miami can no longer be dismissed."(BURT, s/d.). Para o governo norte-americano, a Colômbia representava uma séria ameaça à segurança nacional e regional.

Em contrapartida, governo colombiano sob a administração Pastrana (1998-2002) tinha como objetivo principal combater o avanço da violência em território colombiano. Com o Plan Nacional de Desarrollo (PND) "Cambio para construir la paz 1998-2002" (COLOMBIA,1999), de um lado, focava-se na solução negociada com os movimentos insurgentes, e, de outro, defendia que o cultivo de substâncias ilícitas - principal combustível do conflito armado - era, antes de tudo, um problema social que deveria ser tratado de forma multilateral como uma espécie de "Plano Marshall" para a Colômbia. O Plano previa ampliar programas de promoção de desenvolvimento social e econômico, de modo que o combate direto ao tráfico de drogas fosse considerado uma questão acessória. Nos EUA, encarou-se com grande preocupação a intenção de Pastrana de promover as negociações de paz com as FARC; nesse período, o Congresso norte-americano aprovou uma resolução que estipulava o corte da assistência antinarcóticos a Colômbia, caso as iniciativas de Pastrana e o plano proposto de conceder uma zona desmilitarizada às FARC interferissem no processo de erradicação das plantações de coca (ROSEN, 2013; TICKNER, 2007).

A "diplomacia por la paz" do governo Pastrana formalizou a internacionalização do conflito colombiano ao passo que solicitou cooperação de múltiplos atores externos, no entanto, com a falta de envolvimento da comunidade internacional, sobretudo no auxílio financeiro eas dificuldades estruturais para cumprir os objetivos declarados, inviabilizou-se a estratégia inicial do governo, resultando numa relativa ineficácia (ROSEN, 2013; SANTOS, 2010; TICKNER, 2007).Assim, altera-se a perspectiva a ponto de recorrer a uma aliança tática com os EUA, de modo que, na busca pela resolução de seus problemas internos, adotou-se uma linguagem que os norte-americanos estariam dispostos a cooperar: o governo colombiano apresentou a Colômbia como um país "problema" que era incapaz de garantir o monopólio estatal do uso da força e promover o controle do território frente o avanço do poder do narcotráfico e das guerrilhas. Para Tickner (2007 p.100), a visão empregada pelo governo colombiano "al desarrollar una imagen de país en estos términos el gobierno colombiano participó activamente en la construcción de su propia inferioridad, lo cual consideraba indispensable para asegurar la ayuda de Washington.".

Dessa nova perspectiva, em 1999, nascia o Plano Colômbia, também conhecido pelo nome de Plan para la paz, la prosperidade y el fortalecimiento del Estado, escrito primeiramente em inglês e baseado essencialmente na política antidrogas norte-americana. O Presidente Clinton aprovou o Plano Colômbia como lei em 2000. Dentre os motivos que o levaram a aprovar o Plano estava a necessidade de responder às críticas dos Republicanos (que argumentavam que Clinton era brando no combate ao narcotráfico) e a crise institucional (frente à revelação de seu envolvimento sexual com Monica Lewinsky) (ROSEN, 2013; TATE, 2015). Clinton, em discurso, reforça a retórica do narcotráfico como "inimigo americano", afirmando que

the major security threat this country will face will come from the enemies of the nation state: the narco-traffickers and the terrorists and the organized criminals, who will be organized together, working together, with increasing access to ever-more sophisticated chemical and biological weapons. (Discurso de Bill Clinton. Estados Unidos, 2000).

De acordo com o texto original, o Plano Colômbia possuía estratégias tanto no campo militar quanto no campo econômico social. A estratégia antinarcóticos tinha como meta, para os próximos seis anos, reduzir em 50\% o cultivo, o 


\section{NEIBA}

processamento e a distribuição dos narcóticos (USIP, 2000 p.13).

strengthen the fight against narco-trafficking by bringing all elements of the Police and Armed Forces to bear against the traffickers. The goal is to eliminate large-scale drug production, end large-scale violence and lawlessness by organized armed groups, promote respect for human rights and break the link between armed groups and their narcotics industry support (USIP, 2000. p. 16).

Inicialmente para durar até dezembro de 2005, previa assistência do principal programa de suporte dos EUA - Andean Counter drug Initiative $(\mathrm{ACl})$ - com um total aproximado de US\$2.8 bilhões de dólares, e a assistência do programa Foreign Military Financing (FMF) e do Department of Defense(DOD) comum investimento de US\$4.5 bilhões (US CONGRESSIONAL RESEARCH SERVICE - CRS, 2006).A estratégia de distribuição dos recursos era: $80 \%$ para 0 considerado "hard components" - ajuda militar, material, fumigação aérea", entre outros - e somente $20 \%$ para "soft programs" como alternativas de desenvolvimento sustentável. Ainda que o Plano contemplasse propostas sociais, econômicas, políticas, jurídicas e de Direitos Humanos, o que prevaleceu como eixo central foi o caráter bélico, priorizando o combate no lado da oferta e ignorando problemas subjacentes como a demanda e o fortalecimento das instituições (ROSEN, 2013; TATE, 2015; TICKNER, 2007).

O argumento formulado pelo governo Pastrana para executar o Plano era que o Estado por si só era demasiadamente débil para enfrentar o problema das drogas sozinho, assumindo que o narcotráfico era uma questão de segurança interna,

\footnotetext{
9 De acordo com Camacho e Mejía (2014), as campanhas de fumigação eram geralmente executadas por empresas norte-americanas como a DynCorp e estas utilizavam substâncias como o Roudup, um herbicida criado pela Monsanto.
}

we must acknowledge that more than twenty years after marijuana cultivation come to Colombia, along with increased cocaine and poppy cultivation, drug trafficking continues to grow as a destabilizing force, distorting the economy, reversing the advances made in land distribution, corrupting society, multiplying violence, depressing the investment climate and most seriously, providing increased resources to fund all armed groups(USIP, 2000, p.3).

Reafirmando ainda o papel fundamental da militarização nesse combate, "our success also requires reforms at the very heart of our institutions, in particular, in our military forces to uphold the law and return a sense of security to all Colombians everywhere in Colombia"(USIP, 2000, p.3).O Plano favorecia os interesses dos dois países que não eram necessariamente os mesmos: da perspectiva colombiana, o Plano Colômbia exercia uma função dupla: fortalecer o Estado por meio da melhora de seu aparato militar e isolar as FARC de uma de suas principais fontes de financiamento; no caso dos EUA mostrava determinação na "guerra às drogas". (TICKNER e CEPEDA, 2011). Assim, ao passo que a Colômbiadependia dos recursos econômicos e do apoio norte-americano, os EUA controlavam a destinação desses recursos de acordo com suas estratégias e objetivos de política externa. Em última análise, a relação assimétrica de ajuda dos EUA define as regras e políticas aplicadas (ROSEN, 2013).É, portanto, nesse sentido, que alguns autores defendem que o caso colombiano trata-se de uma "intervención por invitación", pelo qual o governo colombiano utilizou como estratégia a intensa associação com o governo estadunidense visando à ingerência norte-americana no conflito interno do país (TICKNER, 2007).

11 de setembro e a incorporação da "guerra às drogas" pela "guerra ao terror"

Os ataques de 11 de setembro de 2001 e a virada na política exterior norte-americana afetaram as relações 


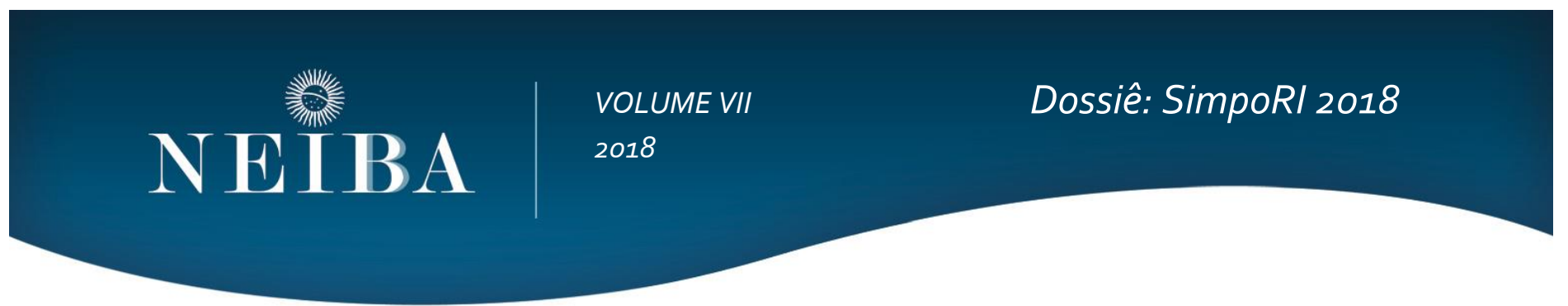

bilaterais com a Colômbia, uma vez que "in terms of U.S. foreign policy, everything became subordinated to the war on terror" (ROSEN, 2013 p.73). Assim, a política oficial de Washington sob o governo Clinton -que tinha como foco o combate à "narcodemocracia" colombiana - passa a ser convertida, durante o governo de George W. Bush (20012009), na luta contra o "narcoterrorismo" (LINTON, 2015). A ajuda financeira oferecida à Colômbia pelo Plano Colômbiaque, oficialmente, era limitada pelo Congresso norte-americano àsações de combate ao narcotráfico apesar de ter tido um caráter anti-insurgente de forma velada - obteve em 2002, aprovação do legislativo norteamericano para ser utilizada também na luta antiterrorista. Assim, a distinção, que já era tênue, entre a luta antinarcóticos e a anti-insurgente, funde-se completamente. (TICKNER e CEPEDA, 2011; SANTOS, 2010).

A administração Bush e os neoconservadores converteram a "guerra às drogas"em apêndice da "guerra mundial contra o terrorismo", colocando as FARC, o ELN e a AUC na lista de organizações terroristas do Departamento de Estado dos $E A^{10}$. A partir do processo de securitização, salientou-se a importância do combate ao tráfico de drogas e atividades criminosas que ajudavam a financiar grupos insurgentes, com o objetivo de "vender" a importância do financiamento de operações antinarcóticos para o público norte-americano e em especial naqueles locais em que os fenômenos convergiam (TICKNER e CEPEDA, 2011; ROSEN, 2013). Ainda assim, a inclusão desses grupos como terroristas pelo governo norte-americano não significou a mesma identificação por parte do governo colombiano. O governo de Pastrana manteve até 2002 a posição de seu discurso na Assembleia Geral das Nações Unidas realizado em 2001 - dias antes do ataque às Torres Gêmeas -,

las FARC son las únicas que tienen la capacidad de definir cómo y de qué forma quieren que

${ }^{10}$ Ver Patterns of Global Terrorism, 2000. Disponível em: http://www.state.gov/j/ct/rls/crt/200o/index.htm la comunidad internacional los mire a ellos. Si quieren que los vean como terroristas, como narcotraficantes o como una organización guerrillera que quiere la solución política del conflicto armado (apud TICKNER, 2009 p.64).

Apesar das manifestações de funcionários ligados ao governo estadunidense que reforçavam o discurso de que as FARC - como organização terrorista - possuíam táticas que eram semelhantes às de Osama Bin Laden, representando uma clara ameaça à estabilidade regional (TICKNER, 2007), a posição do governo colombiano de não tratá-la como grupo terrorista se manteve até o dia 20 de fevereiro de 2002, quando Pastrana põe fim ao processo de paz com as FARC e afirma em rede nacional que "hoy la guerrilla está desenmascarada y ha mostrado su verdadera cara, la cara de la violência sin razón, ante el mundo [....] ya nadie puede dudar de que, entre política y terrorismo, las FARC optaron por el terrorismo"(BBC, 2002) ${ }^{11}$.

Com a mudança no discurso colombiano, o país inseriu-se de vez dentro do novo mapa de prioridades de Washington. Ainda que, tanto as FARC como a AUC possuíssem comprovada participação nas etapas da economia da droga, o fato das FARC terem assassinado e sequestrado cidadãos estadunidenses ${ }^{12}$ e avançado suas ações durante o processo de negociação com o governo Pastrana resultou em uma ênfase quase que exclusivasobre este grupo nos discursos oficiais (TICKNER, 2007). Assim, as FARC cujas práticas eram agora reprovadas por quase todos os colombianos, mas cujas demandas originais eram apoiadas pela maioria, era desacreditada como movimento guerrilheiro e apresentada ao resto do mundo como algo pior que uma organização terrorista, como afirma Linton (2015 p.72)"desde entonces, El gobierno colombiano, EEUU y una

${ }^{11} \mathrm{O}$ discurso completo do presidente pode ser visto em:http://news.bbc.co.uk/hi/spanish/latin_america/newsid_1834000/183428 8.stm.

${ }^{12}$ As FARC sequestraram e assassinaram três indigenistas norte-americanos no departamento de Arauca em 1999. 


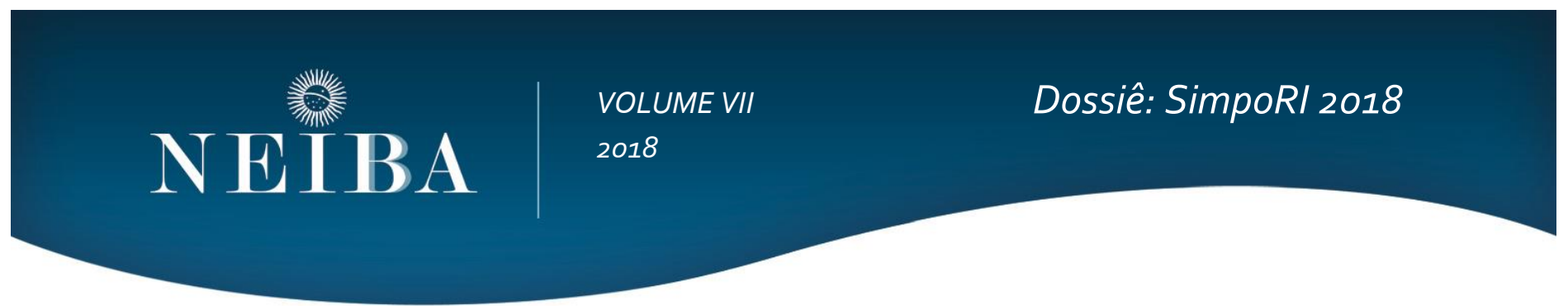

gran parte de la Unión Europea lãs verían prácticamente como una mafia dedicada al tráfico de drogas".

Nesse momento, a Colômbia vira um caso de "narcoterrorismo" e dissemina-se a ideia de que o conflito colombiano é a maior ameaça terrorista do hemisfério ocidental, na qual a interferência do governo estadunidense é apresentada quase que como um dever, como anuncia o Procurador Geral dos EUA, John D. Ashcroft, "just as we fight terrorism in the mountains of South Asia, we Will fight terrorism in our own hemisphere". (THE WASHINGTON POST, 2002).Para Rosen (2013), Uribe consegue alterar as metas do Plano Colômbia bem como as percepções do conflito armado interno, transformando este em um problema de cunho terrorista e uma ameaça continental.Assim, o emprego do discurso antiterrorista permitiu corrigir as incompatibilidades, pelo menos as formais, que existiram no governo Pastrana,entre o conteúdo militar do Plano Colômbia e a realização de um processo de paz com as FARC. A convergência dos objetivos e estratégias de ambos os governos resultou, portanto, na aplicação mais direta e ousada da "guerra às drogas" internamente e um alinhamento estratégico com Washington na "guerra ao terror" no plano internacional (TICKNER, 2007).

Cabe, nesse sentido, recordar o conceito de overlay de Buzan e Waever (2003), quando a presença de uma potência externa interfere nas dinâmicas de segurança de uma região.A presença direta dos Estados Unidos no conflito colombiano a partir de um alinhamento de políticas de segurança realizadas por meio do aparato discursivo iniciadas com o Plano Colômbia, mas estabelecidas, principalmente, após os ataques de 11/9 -, e a incorporação da luta contra as drogas na luta mundial contra o terrorismo,com a qualificação dos grupos guerrilheiros como grupos terroristas,influenciou e orientou as dinâmicas da agenda de segurança em território colombiano. Esse alinhamento garantiu a sobreposição dos interesses de segurança da potência externa, configurando, portanto, um caso de overlay.

Com a política do governo Uribe houve o crescimento das áreas de fumigação, o aumento das apreensões de drogas, da destruição de laboratórios e a intensificação da extradição de colombianos para os EUA (TICKNER e CEPEDA, 2011). Uribe iniciou uma campanha militar em meados de 2003, chamada Plan Patriota, com o objetivo de recuperar territórios controlados pelas FARC no sul e no leste do país; aoperação era coordenada entre o Exército, as Força Aérea e Armada, a polícia e o Departamento Administrativo de Segurança e com o apoio, assessoria e monitoramento do governo norte-americano com o South com (Consultoría para los Derechos Humanos y el Desplazamiento - CODHES, 2004). De acordo com o US Congressional Research Service(2005), até 2005, o governo colombiano conseguiu retomar o controle de 11 aldeias das FARC e destruir mais de 400 acampamentos. Ademais, desarticularam a frente das FARC em Cundinamarca e capturaram ou mataram os principais chefes das frentes localizadas perto de Bogotá, por exemplo, o comandante do Boque Oriental, Marco Aurelio Buendía, em 2003 (SEMANA, 2006; EL PAÍS, 2003).O Plano propiciou uma intensificação nas relações entre EUA e Colômbia, com o propósito de aumentar as capacidades ofensivas das Forças Armadas colombianas sendo, portanto, o maior componente militar do Plano Colômbia.

No mesmo ano, Uribe ratifica sua posição sob as linhas de política externa norte-americana e admite que "el gran enemigo de la democracia colombiana es el terrorismo y el gran aliado para derrotar el terrorismo ha sido el pueblo y el Gobierno de los Estados Unidos."(Discurso de Álvaro Uribe na Colômbia, 2005).De modo que, mais uma vez utiliza-se do aparato discursivo e da ideia de inimigo do Estado para reforçar as alianças entre o governo norte-americano e o governo colombiano.

\section{Considerações finais}




\section{NEIBA}

\section{VOLUME VII}

\section{Dossiê: SimpoRI 2018}

\section{8}

De fato, a ingerência dos EUA no conflito colombiano contou com a permissão do governo colombiano. No entanto, como visto, a política de segurança do país andino foi submissa à do governo norte-americano, o aparato discursivo norte-americano moldou uma estratégia repressiva e ofensiva no combate ao que foi qualificado como ameaça à segurança nacional, regional e continental: primeiro, o narcotráfico e, depois, o terrorismo.

O overlay dos interesses norte-americanos garantiu uma política cujo eixo central era o caráter bélico e desde os anos 1970 é possível observar esse transbordamento de interesses. Em um primeiro momento, a criação da "guerra às drogas" e a vinculação dos grupos armados insurgentes colombianos com a economia da droga transportou o discurso e as políticas de combate antinarcóticos dos Estados Unidos para o território colombiano sob o pretexto de combate à "oferta".O resultado, como apresentado, foi o desenvolvimento do Plano Colômbia, a partirda lógica do discurso que declarava uma "guerra" -estratégia fundamentalmente militar que deixava em segundo plano questões econômicas e sociais. Em um segundo momento, com o movimento do governo norte-americano de inserir a "guerra às drogas" na "luta global contra o terrorismo" e anunciar os grupos armados como terroristas. Quando o governo colombiano incorporou a retórica de não diferenciar a insurgência e o terrorismo, unificando fenômenos como o narcotráfico, as guerrilhas, o discurso de guerra deu lugar à prática mais ofensiva. O conflito colombiano passa de uma retórica ligada as "narcoguerrilhas" e de exemplo de uma "narcodemocracia" para um caso de "narcoterrorismo". A criação do Plano Patriota, em 2002, resultado desse processo de incorporação discursiva, representou o maior componente militar do Plano Colômbia. Este possibilitou o fortalecimento militar da Força Pública e a campanha ofensiva que causou, posteriormente, o enfraquecimento das guerrilhas. 


\section{NEIBA}

VOLUME VII

Dossiê: SimpoRI 2018

2018

\section{BIBLIOGRAFIA}

BBC. Que San Miguel Arcángel nos proteja: Pastrana. 21 de febrero de 2002. Disponivel em:http://news.bbc.co.uk/hi/spanish/latin_america/newsid_1834000/1834288.stm

BUONO, Richard A. Dello. El Plan Colombia/ La Iniciativa Regional Andina: ¿ Hacia la Guerra o la Concertación? Foro Nacional de Análisis de Relaciones Internacionales en la Ciudad de Panamá. Panamá, Octubre, 2001. Disponível em: http://www.ieeiunesp.com.br/portal/wp-content/uploads/2011/1o/El-Plan-Colombia-la-iniciativa-regional-andina-hacia-la-guerra-o-la-concertacionRichard-Buono.pdf

BURT, Jo-Marie. A Call to Arms. s/d. Disponivel em: https://nacla.org/article/call-arms

BUZAN, Barry; HANSEN, Lene. A evolução dos estudos de segurança internacional. São Paulo: Unesp, 2012.

BUZAN, Barry; WAEVER, Ole. Regions and Powers: The Structure of International Security. Cambridge, UK: Cambridge University Press, 2003.

BUZAN, Barry; WAEVER, Ole; WILDE, Jaap de. Security: A New Framework for Analysis. Cambridge, US: Lynne Rienner Publishers, 1998.

CLINTON, Bill. DiscursoproferidonosEstadosUnidos, 2000. Disponívelem: http://www.washingtonpost.com/wp-

srv/politics/special/states/docs/sovoo.htm

COLOMBIA. Decreto No356 de 1994. Disponível em: http://190.248.87.7/Siaem/normatividad/Decreto_356_1994.pdf

COLOMBIA.Plan nacional de desarrollo (1998-2002 cambio): para construir la paz, 1999. Disponívelem:

https://colaboracion.dnp.gov.co/cdt/pnd/pastrana2_contexto_cambio.pdf

CONSULTORÍA PARA LOS DERECHOS HUMANOS Y EL DESPLAZAMIENTO - CODHES, 2004. Disponível em:

http://www.acnur.org/t3/uploads/media/638.pdf?view=1

CRANDALL, Russel. Driven by drugs: U.S policy toward Colombia. Boudel, CO: Lynne Rienner. 2002

DUQUE, Marina Guedes. O papel de sintese da escola de Copenhague nos estudos de segurança internacional. Contexto int. [online]. 2009, vol.31, n.3, pp.459-501. Disponível em: http://www.scielo.br/pdf/cint/v31n3/v31n3a03.pdf

EL PAÍS. 'Marco Aurelio Buendía' fue abatido por Ejército. 2003. Disponível em:

http://historico.elpais.com.co/paisonline/notas/Noviembreo12003/A501N1A.html

GLOBAL DRUG POLICY OBSERVATORY - GDPO. 2016 Disponivel em: http://gdpo.swan.ac.uk/?p=440 


\section{NEIBA}

GRUPO DE MEMÓRIA HISTÓRICA - GMH. ¡BASTA YA! Colombia: Memorias de guerra y dignidad. Bogotá: Imprenta Nacional, 2013. Disponível em: http://www.centrodememoriahistorica.gov.co/descargas/informes2013/bastaYa/basta-ya-memorias-guerra-dignidadnew-9-agosto.pdf

GUTKIN, Steven. Dea Agent Attacks Colombia As 'Narco-Democracy'. The Washington Post, Washington, October 1. 1994. Disponívelem: https://www.washingtonpost.com/archive/politics/1994/10/o1/dea-agent-attacks-colombia-as-narcodemocracy/41018ge6-0878-48b9-925a-127ce47148f1/?noredirect=on\&utm_term=.a327ece6864f

HERITAGE FOUNDATION. How the Clinton Administration is Abandoning the War Against Drugs, 1994.Disponivel em: http://www.heritage.org/research/reports/1994/o6/bgg8gnbsp-how-the-clinton-administration

LINTON, Magnus. La guerra contra las drogas: 69 de Richard Nixon a Barack Obama. In: Nueva Sociedad. N.255. 2015 Disponível em: http://library.fes.de/pdf-files/nuso/nuso-255.pdf

MALAMUD-GOTI, Jaime. Soldiers, peasants, politicians and the War on Drugs in Bolivia. American University International Law Review, v. 6, p. 55, 1990. Disponívelem:

https://digitalcommons.wcl.american.edu/cgi/viewcontent.cgi?referer=https://www.google.com.br/\&httpsredir=1\&article=1550\&conte $x t=$ avilr

NIXON, Richard. Discurso proferido nos Estados Unidos, 1971. Disponível em http://www.presidency.ucsb.edu/ws/?pid=3047

PÉCAUT, Daniel. Las FARC: fuentes de su longevidad y de la conservación de su cohesión. Análisis político, Bogotá n. 63, p. 22-50, mayo-agosto. 2008.

PROCOPIO FILHO, Argemiro; VAZ, Alcides Costa. O Brasil no contexto do narcotráfico internacional. In: Revista Brasileira de Política Internacional, Brasília, v. 40, n. 1, p. 75-122, Jun. 1997. Disponível em: http://www.scielo.br/scielo.php?script=sci_arttext\&pid=Soo34$73291997000100004 \& \operatorname{lng}=e n \& n r m=i s o$

RODRIGUES, Thiago. Narcotráfico e Militarização nas Américas: Vício de Guerra In: Contexto Internacional, Rio de Janeiro, vol. 34, no 1, janeiro/junho 2012, p. 9-41.Disponível em: http://www.scielo.br/pdf/cint/v34n1/v34n1a01.pdf

ROJAS, Diana. El taller del imperio global: Análisis de la intervención de Estados Unidos en Colombia (1998-2008). AnálisisPolítico, Bogotá, n. 65, p. 111-126, enero-abril. 2009.

ROSEN, Jonathan. The war on drugs in Colombia: A current account of U.S. policy. In: Perspectivas Internacionales. Vol. 9, n. 2, 2013. Disponível em http://revistas.javerianacali.edu.co/index.php/perspectivasinternacionales/article/download/1011/1582

SANTOS, Marcelo. A política dos estados unidos de combate ao Narcotráfico e o plano colômbia (1998-2005). In: Estudos de Sociologia. Araraquara, v.12, n.22, p.169-188, 2007. Disponível em: https://periodicos.fclar.unesp.br/estudos/article/view/354

SANTOS, Marcelo. Passado e presente nas relações Colômbia-Estados Unidos: a estratégia de internacionalização do conflito armado colombiano e as diretrizes da política externa norte-americana. Revista Brasileira de Política Internacional. Brasília, v. 53, n.1. jan-julh, 2010. Disponível em: http://www.scielo.br/scielo.php?pid=s0034-73292010000100004\&script=sci_arttext 


\section{NEIBA}

SEMANA. Plan Patriota. 2006. Disponível em: http://www.semana.com/on-line/articulo/plan-patriota/70525-3

TANNO, Grace. A Contribuição da Escola de Copenhague aos Estudos de Segurança Internacional. Revista Contexto Internacional, Rio de Janeiro, vol. 25, n.1 jan-jun. 2003. Disponível em http://contextointernacional.iri.puc-rio.br/media/Tanno_vol25n1.pdf

TATE, Winifred. Drogas, Bandidos y Dipomáticos: Formulación de política pública de Estados Unidos hacia Colombia. Bogotá: Universidad del Rosário, 2015.

THE WASHINGTON POST. Colombian Rebels Are Indicted as Terrorists. 2002. Disponível em:https://www.washingtonpost.com/archive/politics/2002/05/01/colombian-rebels-are-indicted-as-terrorists/12agogfb-1bbc-4e6o$895 f-4 d c 2 b 047 b a 2 d /$

TICKNER, Arlene. Intervención por Invitación: Claves de la política exterior colombiana y de sus debilidades principales. Colombia Internacional, Bogotá, n.65, p.90-111, enero-jun. 2007. Disponível em:http://colombiainternacional.uniandes.edu.co/view.php/93/view.php

TICKNER, Arlene. Desafíos de seguridad en Colombia: Internacionalización del conflicto armado y la relación "especial" con los Estados Unidos. In: Relaciones Internacionales:los Nuevos Horizontes. FLACSO: Ecuador, 2009.

Disponível em: http://biblio.flacsoandes.edu.ec/catalog/resGet.php?res/d=41512

TICKNER, Arlene; CEPEDA, Carolina. Las drogas ilícitas en la relación Colombia-Estados Unidos: Balance y perspectivas. In: Políticas antidroga en Colombia: éxitos, fracasos y extravíso. 2011.

TICKNER, Arlene; GARCÍA, Diego; ARREAZA, Catalina. Actores violentos no estatales y narcotráfico en Colombia.In: Políticas antidroga en Colombia: éxitos, fracasos y extravíso. 2011.

UNITED STATES INSTITUTE OF PEACE - USIP. Plan Colombia, 2000 Disponívelem: http://www.usip.org/sites/default/files/plan_colombia_101999.pdf

UNITED STATES. National Security Decision Directive 221 - NSDD-221. 1986. Disponível em: http://fas.org/irp/offdocs/nsdd/nsdd221.pdf

UNITED STATES. NationalDrugControlStrategy, 1994. Disponível em: https://www.ncjrs.gov/pdffiles1/ondcp/150489.pdf UNITED STATES. National Security Directive 18-NSD-18. 1989. Disponivel em: http://fas.org/irp/offdocs/nsd/nsd18.pdf URIBE, Álvaro. Discurso proferido na Colômbia, 2005. Disponível em: http://historico.presidencia.gov.co/discursos/discursos2005/agosto/rueda_deprensa.htm

US CONGRESSIONAL RESEARCH SERVICE - CRS. Certification/Designation Procedures for Illicit Narcotics Producing and Transit Countries. September 22, 2003. Disponível em: http://research.policyarchive.org/1813.pdf

US CONGRESSIONAL RESEARCH SERVICE - CRS. Plan Colombia: A Progress Report, January 11, 2006. Disponívelem: https://wikileaks.org/wiki/CRS-RL32774 